\title{
Structure and factors of the risk of premature birth
}

\author{
Aizada Marat ${ }^{1}$, Talshyn Ukybassova ${ }^{2}$
}

${ }^{\prime}$ Obstetric department №2, "University Medical Center"National Research Center for Maternal and Child Health, Astana, Kazakhstan.

${ }^{2}$ Department of Women's Diseases, "University Medical Center"National Research Center for Maternal and Child Health, Astana, Kazakhstan.

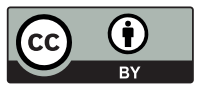

This work is licensed under a Creative Commons Attribution 4.0 International License
J CLIN MED KAZ 2017; 3(45 SUPPL 3):14-17 Автор для корреспонденции: Марат Айзада, Акушерское отделение №2, "University Medical Center” Национальный научный центр материнства и детства. Адрес: Казахстан, Астана, пр. Туран, 32. Тел.: +77057837472

E-mail: Aizadamarat0708@gmail.com;

\section{ABSTRACT}

Objective. To study the structure and risk factors of premature birth.

Methods. Prospective open-label non-randomized clinical trial. The study included 11861 births, including 1806 - premature (15.2\%) in the CF "UMS of the National Research Center for Maternity and Childhood." The odds ratio (OR), the confidence interval (CI) of risk factors for the development of preterm birth have been calculated.

Results. When studying the social portrait of prematurely giving birth to women: the level of education (OR - 2.7, SE - 0.29, CI (95\%) 1.5-4.8; ) employment (OR-2.4, SE-0, 29; CI (95\%) 1.3-4.1;) and the woman's place of residence (OR 1.5, SE 0.29 , CI 95\% 0.9-2.7) are statistically significant risk factors for premature birth. The study of obstetrical anamnesis of pregnant women revealed the following: $14.2 \%$ - primitive, $85.8 \%$ - repeat pregnancy, $26.3 \%$ - with a syndrome of previous perinatal losses ( 2 or more spontaneous abortions), $32.2 \%$ - previous premature births, 2, 4\% - with cervical insufficiency.

Conclusion. The main risk factors for premature birth are cervical insufficiency, repeated pregnancies with a parity of more than 4 (OS-1.19, SE-0.3, CI (95\%) 0.7-2.2;), the presence of premature birth and fetal loss in the history (OR-2.66, SE-0.35, CI (95\%), 1.3-5.3;), birth of small children (OR-2.38; SE0.37; CI (95\%) 1.2-5.1;).

The social portrait of women with preterm birth appears as follows: age 20 to 34 years, predominantly in rural areas, housewives with low and medium education, with habitual loss of pregnancy or previous premature birth, cervical insufficiency.

Family planning, pre-birth training for a prospective mother and conducting preventive measures in pregnant high-risk groups for premature birth can be a condition for reducing the frequency of preterm labor.

Key words: premature births, structure and factors of the risk of premature birth.

ТҰЖЫРЫМДАМА

МЕРЗІМІНЕН БҰРЫН БОСАНУ ҚҰРЫЛЫМЫ ЖӘНЕ ҚАУІП ЖАҒДАЙЛАРЫ

Айзада Марат ${ }^{1}$, Талшын Укібасова ${ }^{2}$

'№2 акушерлік бөлімше, “University Medical Center” Ана мен бала ұлттық ғылыми орталығы, Астана, Қазақстан.

Әйелдер аурулары бөлімшесі, “University Medical Center” Ана мен бала ұлттық ғылыми орталығы, Астана, Қазақстан.

Мақсаты.Мерзімінен бұрын босану құрылымы және даму қауіп жағдайларын меңгеру.

Зерттеудің әдістері. Проспективтік ашық рандомизирленбеген клиникалық зерттеу. Зерттеуге «Ана мен бала ұлттық ғылыми орталығында UMC» КФ 11861 босану кіргізілді, оның ішінде 1806 (15,2\%) мерзімінен бұрын босану. Мерзімнен бұрын босану дамуының мүмкіншілік арақатынасы (МА), сенімгерлік межелдемесі (СМ) есептелді.

доверительного интервала (ДИ) фракторов риска развития преждевременных родов.

Нәтижелері. Мерзімінен бұрын босанған әйелдердің әлеуметтік бейнесі зерттеу кезінде: білім деңгейі (OШ - 2,7; SE - 0,29; ДИ (95\%) 1,5-4,8;), жұмысбастылық (ОШ-2,4; SE - 0,29; ДИ (95\%) 1,3-4,1;) және әйелдің тұрғылықты жері (OШ - 1,5;SE - 0,29; ДИ (95\%) 0,9-2,7;) мерзімінен бұрын босану дамуының статистикалық маңызы бар фракторлары болып табылады.

Акушерлік анамнезін тексеру барысында келесі анықталды: 14,2\% - алғаш жүктілер, 85,8\% - қайта жүктілер, 26,3\% - алдында болған перинаталдық жоғалту синдромымен (2 және жоғары өздігінен түсіктер), 32,2\% - алдында болған мерзімінен бұрын босанулар, 2,4\% цервикальдық жетіспеушлік.

Қорытынды. Истмикалық- цервикалдық жетіспеушлік, 4-тен жоғары босанулар (ОШ-1,19; SE - 0,3; ДИ (95\%) 0,7-2,2;), анамнезінде мерзімнен бұрын босану және перинаталдық жоғалтулардың болуы (ОШ-2,66; SE - 0,35; ДИ (95\%) 1,3-5,3;), салмағы аз балалардың туылуы (ОШ-2,38; SE - 0,37; ДИ (95\%) 1,2-5,1;) мерзімінен бұрын босанудың негізгі даму факторлары болып табылады. 
Мерзімінен бұрын босанумен әйелдердің әлеуметтік бейнесі келесідей: 20-34 жас аралығы, басым бөлігі ауылдық жерде тұратын, орташа білім деңгейімен, қайта босанушылар, үйреншікті жүктілікті жоғалтумен немесе алдында болған мерзімінен бұрын босанулармен, истмикалық- цервикалдық жетіспеушлік.

Жүктілікті жоспарлау, болашақ аналарды жүктілік алды даярлау және мерзімінен бұрын босану бойынша жоғары қауіп тобы жүктілеріне алдын алу шараларын жүргізу мерзімінен бұрын босану жиілігін төмендету үшін жағдай болуы мүмкін.

Маңызды сөздер: мерзімінен бұрын босану, мерзімінен бұрын босану құрылымы және даму факторлары.

\section{СТРУКТУРА И ФАКТОРЫ РИСКА ПРЕЖДЕВРЕМЕННЫХ РОДОВ}

\section{Айзада Марат ${ }^{1}$, Талшын Укыбасова ${ }^{2}$}

${ }^{1}$ Акушерское отделение №2, “University Medical Center” Национальный научный центр материнства и детства, Астана, Казахстан.

${ }^{2}$ Отделение женских болезней, “University Medical Center” Национальный научный центр материнства и детства, Астана, Казахстан.

\section{РЕЗЮМЕ}

Цель исследования. Изучить структуру и факторы риска развития преждевременных родов.

Методы. Исследование проспективноеоткрытое нерандомизированное клиническое. В исследование включены11 861 родов, в том числе 1806 - преждевременных (15,2\%) в КФ «UMC Национального научного центра материнства и детства». Проведен расчет отношения шансов (ОШ), доверительного интервала (ДИ) факторов риска развития преждевременных родов.

Результаты. При изучении социального портрета преждевременно родивших женщин: уровень образования (ОШ - 2,7; SE - 0,29; ДИ (95\%) 1,5-4,8;), занятость (ОШ-2,4; SE - 0,29; ДИ (95\%) 1,3-4,1;) и место проживания женщины (ОШ - 1,5;SE - 0,29; ДИ (95\%) 0,9-2,7;) являются статистически значимыми факторами риска развития преждевременных родов.

Изучение акушерского анамнеза беременных выявило следующее: 14,2\% - первобеременные, 85,8\% - повторбеременные, 26,3\% - с синдромом предшествующих перинатальных потерь (2 и более самопроизвольных выкидыша), 32,2\% - предшествующие преждевременные роды, 2,4\% - с цервикальной недостаточностью.

Выводы.Основными фракторами риска развития преждевременных родов являются истмико-цервикальная недостаточность, повторные беременности с паритетом более 4-х(ОШ-1,19; SE - 0,3; ДИ(95\%) 0,7-2,2;), наличие преждевременных родов и потерь плода в анамнезе(ОШ-2,66; SE - 0,35; ДИ(95\%) 1,3-5,3;), рождение маловесных детей(ОШ-2,38; SE - 0,37; ДИ (95\%) 1,2-5,1;).

Социальный портрет женщин с преждевременными родами выглядит следующим образом: возраст от 20 до 34 лет, преимущественно проживающие в сельской местности, домохозяйки, с низким и средним уровнем образования, повторнородящие, с привычной потерей беременности или предшествующими преждевременными родами, истмико-цервикальную недостаточность.

Планирование семьи, предгравидарная подготовка будущей матери и проведение профилактических мероприятий у беременных групп высокого риска по преждевременным родам может быть условием для снижения частоты преждевременных родов.

Ключевые слова: преждевременные роды, фракторы риска, структура.

\section{Введение}

Несмотря на достижения медицинской науки, во всем мире по данным Всемирной организации здравоохранения (ВО3) ежегодно 15 миллионов детей рождаются «слишком рано», более 1 миллиона этих детей ежегодно умирают. По данным ВОЗ показатель преждевременных родов в Республике Казахстан на 100 случаев родов за 2010г. составил 8.8[1].

С 1 января 2008 года в организациях здравоохранения Казахстана случаи рождения и смерти детей регистрируется в соответствии с критериями ВОЗ.По официальным данным частота преждевременных родов в Казахстане за последние 5 лет остается в пределах - 6,4\%.

Цель исследования: анализ структуры и факторов риска преждевременных родов.

\section{Материалы и методы}

Проведено проспективное открытое нерандомизированное клиническое исследование. Всего проанализировано11 861истории родов, в том числе 1806 - преждевременных $(15,2 \%)$ вКФ «UMC Национального научного центра материнства и детства». Проведен расчет отношения шансов (ОШ), доверительного интервала (ДИ) факторов риска развития преждевременных родов. Возраст преждевременно родивших женщин колебался от 18 до 42 лет. Средний возраст $29,2 \pm 3,4$ года.

\section{Результаты}

Показатель преждевременных родов составил 15\%, что выше среднего показателя Республики в два раза и это обусловлено концентрацией пациентов с тяжелой акушерской и экстрагенитальной патологией из регионов страны.
Структура преждевременно родившихся новорожденных выглядит следующим образом: с массой тела 1500-2499 грамм 69,7\% (n=1352), с массой тела 1000-1499,0 грамм $18,7 \%$ (n=363), с массой тела 500-999 грамм - 11,6\% (n=227). Следовательно, в структуре преждевременных родов 70\% роды в сроке от 32 недель 0 дней до 36 недель 6 дней; около $18 \%$ - от 28 недель 0 дней до 31 недель 6 дней; и 12\% - от 22 недель до 27 недель 6 дней.

В структуре причин преждевременных родов превалируют преждевременное родоразрешение по медицинским показаниям - 76,7\%, из них индуцированные преждевременные роды - 16\%, преждевременное оперативное родоразрешение - 60,7\%, спонтанные преждевременные роды составили - 23,3\%, в том числе преждевременные роды в результате дородового излитие околоплодных вод 11,5\%. Следовательно, половина спонтанных преждевременных родов начинается с преждевременного дородового излития околоплодных вод.

Основными причинами индуцированных преждевременных родов явились показания со стороны матери гипертензивные состояния - 33\% и нарушения функционального состояния внутриутробного плода $-25 \%$. Преждевременно были родоразрешены путем индукции родов и кесарево сечения в 33\% случаев беременные с тяжелой преэклампсией, эклампсией и HELLP синдромом, в 6,2\% - с осложнениями сахарного диабета, 3,2\% - аномалиями прикрепления плаценты. Одним из серьезных осложнений преэклампсии явилась преждевременная отслойка нормально расположенной плаценты, частота которой при преждевременных родах составила 2,3\% (рис.1). 
Осложнения течения данной беременности

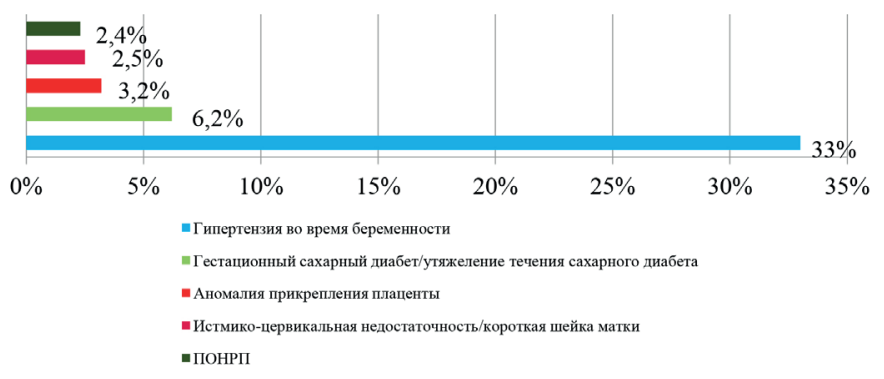

Рисунок 1- Осложнения течения данной беременности.

При изучении социально-демографических факторов преждевременные роды чаще встречаются у женщин в возрасте от 20 до 30 лет 721 (40\%), 30-34 лет 636 (35,2\%).

Среди женщин с преждевременными родами 65\% оказались сельские жители, 62\% - домохозяйки, 57\% - с низким и средним уровнем образования. Отношения шансов социальных показателей приведены в таблице1.

Таблица 1 Оценка факторов риска преждевременных родов с учетом социального анамнеза женщин.

\begin{tabular}{|c|c|c|c|}
\hline $\begin{array}{l}\text { Социально-демографи- } \\
\text { ческие факторы риска }\end{array}$ & $\begin{array}{l}\text { Преждевременные } \\
\text { роды }\end{array}$ & Срочные роды & $\begin{array}{l}\text { Отношение } \\
\text { шансов } \\
\text { (OR } \pm \text { SE) }\end{array}$ \\
\hline \begin{tabular}{|l|} 
Низкий/средний \\
уровень образования
\end{tabular} & $1033(57 \%)$ & 3309 (33\%) & \multirow{2}{*}{$\begin{array}{l}2,7 \\
\text { SE - 0,29 } \\
\text { ДИ (95\%) } \\
1,5-4,8\end{array}$} \\
\hline Высшее образование & $773(43 \%)$ & $6746(67 \%)$ & \\
\hline Домохозяйки & $1124(62 \%)$ & $4085(40,7 \%)$ & \multirow{2}{*}{$\begin{array}{l}2,4 \\
\text { SE - 0,29 } \\
\text { ДИ }(95 \%) \\
1,3-4,1\end{array}$} \\
\hline Работающие & $682(38 \%)$ & $5970(59,3 \%)$ & \\
\hline Сельские жители & $1173(65 \%)$ & $5562(55,3 \%)$ & \multirow{2}{*}{$\begin{array}{l}1,5 \\
\text { SE - 0,29 } \\
\text { ДИ }(95 \%) \\
0,9-2,7\end{array}$} \\
\hline Городские жители & $633(35 \%)$ & $4493(44,7 \%)$ & \\
\hline
\end{tabular}

Таким образом, уровень образования (ОШ - 2,7; SE - 0,29; ДИ (95\%) 1,5-4,8;), занятость (ОШ-2,4; SE - 0,29; ДИ (95\%) 1,3$4,1 ;)$ и место проживания женщины (ОШ - 1,5;SE - 0,29; ДИ (95\%) 0,9-2,7;) являются статистически значимыми факторами риска развития преждевременных родов. Возможно, это связано и с низким социально-экономическим статусом таких семей. Как правило, это пациенты, поступившие из регионов. Из-за трудностей учета нами не были проанализированы такие факторы риска как ежедневные нагрузки в рабочее время (умственная нагрузка, ночная, дневная, напряженная работа, стоячая работа), социально-экономические аспекты: доход семьи и.т.д.

При анализе акушерского анамнеза беременных 14,2\% были первобеременные, 85,8\% - повторбеременные соответственно, $26,3 \%$ - с синдромом перинатальных потерь (2 и более самопроизвольных выкидыша), 32,2\% - предшествующие преждевременные роды, 2,4\% - с цервикальной недостаточностью.

По данным исследований Goldenberg R.L. et al., 2008 наличие одних преждевременных родов в анамнезе увеличивает их риск при последующей беременности в 4 раза, двух преждевременных родов - в 6 раз Преждевременные роды в анамнезе часто ассоциируются с наступлением их в последующем, что нашло отражение в нашем исследовании(таблица2).

\section{Таблица 2}

Оценка факторов риска преждевременных родов с учетом акушерского анамнеза женщин.

\begin{tabular}{|c|c|c|c|}
\hline $\begin{array}{l}\text { Факторы риска } \\
\text { связанные с состоянием } \\
\text { здоровья матери и } \\
\text { плода }\end{array}$ & $\begin{array}{l}\text { Преждевремен- } \\
\text { ные роды } \\
\text { (основная } \\
\text { группа) }\end{array}$ & $\begin{array}{l}\text { Срочные роды } \\
\text { (группа } \\
\text { сравнения) }\end{array}$ & $\begin{array}{l}\text { Отношение } \\
\text { шансов }\end{array}$ \\
\hline \multirow{2}{*}{$\begin{array}{l}\text { Мультипаритет } \\
\text { (4 и более) }\end{array}$} & Да 561 (31\%) & Да 2754 (27,3\%) & \multirow{2}{*}{$\begin{array}{l}1,19 \\
\text { SE - 0,3 } \\
\text { ДИ }(95 \%) \\
0,7-2,2\end{array}$} \\
\hline & Нет 1245 (69\%) & Нет 7301 (72,7\%) & \\
\hline \multirow{2}{*}{$\begin{array}{l}\text { Кесарево сечение в } \\
\text { анамнезе }\end{array}$} & Да $725(40,1 \%)$ & Да 3598 (35,8\%) & \multirow{2}{*}{$\begin{array}{l}1,2 \\
\mathrm{SE}-0,29 \\
\text { ди }(95 \%) \\
0,7-2,1\end{array}$} \\
\hline & Нет 1081 (59,9\%) & Нет 6457 (64,2\%) & \\
\hline \multirow{2}{*}{$\begin{array}{l}\text { Синдром перинаталь- } \\
\text { ных потерь } \\
\text { (самопроизвольные } \\
\text { выкидыши более 2-х) }\end{array}$} & Да $476(26,3 \%)$ & Да 1786 (17,8\%) & \multirow{2}{*}{$\begin{array}{l}1,65 \\
\text { SE }-0,35 \\
\text { ди }(95 \%) \\
0,8-3,2\end{array}$} \\
\hline & Нет 1330 (73,7\%) & Нет 8269 (82,2\%) & \\
\hline \multirow{2}{*}{$\begin{array}{l}\text { Хирургическая/кор- } \\
\text { рекция цервикальной } \\
\text { недостаточности аку- } \\
\text { шерским пессарием. }\end{array}$} & Да 45 (2,5\%) & Да $34(0,3 \%)$ & \multirow{2}{*}{$\begin{array}{l}7,53 \\
\text { SE - 0,22 } \\
\text { дИ(95\%) } \\
0,3-30,0\end{array}$} \\
\hline & Нет 1761(97,5\%) & Нет 10021 99,7\%) & \\
\hline \multirow{2}{*}{$\begin{array}{l}\text { Преждевременные роды } \\
\text { в анамнезе }\end{array}$} & Да 583 (32,2\%) & Да 1524 (15,1\%) & \multirow{2}{*}{$\begin{array}{l}2,66 \\
\text { SE }-0,35 \\
\text { дИ }(95 \%) \\
1,3-5,3\end{array}$} \\
\hline & Нет $1223(67,8 \%)$ & Нет $8531(84,9 \%)$ & \\
\hline \multirow{2}{*}{$\begin{array}{l}\text { Рождение новорож- } \\
\text { денного менее } 2500 \text { г. в } \\
\text { анамнезе }\end{array}$} & Да 487 (27\%) & Да 1347 (13,3\%) & \multirow{2}{*}{$\begin{array}{l}2,38 \\
\text { SE - 0,37 } \\
\text { ди }(95 \%) \\
1,2-5,1\end{array}$} \\
\hline & Нет 1319 (73\%) & Нет 8708 (86,7\%) & \\
\hline
\end{tabular}

Как показывает, таблица 2, статистически значимыми факторами риска,связанными с состоянием здоровья матери и плода, повлиявшими на преждевременные роды были: мультипаритет - 4 и более беременности (ОШ-1,19; SE - 0,3; ДИ(95\%) 0,7-2,2;), наличие рубца на матке после перенесенной операции кесарево сечение(ОШ-1,2; SE - 0,29; ДИ(95\%) 0,7$2,1 ;)$, предшествующие потери беременности(ОШ-1,65; SE - 0,35; ДИ(95\%) 0,8-3,2;), рождение новорожденного с весом менее 2500 граммв анамнезе(ОШ-2,38; SE - 0,37; ДИ (95\%) 1,2-5,1;), предыдущие преждевременные роды (ОШ-2,66; SE 0,35; ДИ(95\%) 1,3-5,3;). Отдельно хотелось отметить значение цервикальной недостаточности - ОШ-7,53; SE-0,22; ДИ(95\%) 0,3-30,0- в развитии преждевременных родов.

Экстрагенитальные заболевания явились фоном для развития осложнений беременности и преждевременного родоразрешения у каждой третьей пациентки. Среди экстрагенитальных заболеваний основные позиции занимали заболевания крови (анемии, тромбоцитопении) - 33\%, заболевания сердечно-сосудистой системы (артериальная гипертензия, врожденные и приобретенные пороки развития сердца) - 10,9\%, заболевания мочевыделительной системы $-6,7 \%$ и органов пищеварения $-4,5 \%$. Полученные результаты подтверждают данные ВО3 (Morisaki N. et al., 2014), указывающие на анемию как фактор риска преждевременных родов, особенно в экономически слаборазвитых странах.

Нарушения соматического здоровья пациентов с преждевременными родами определили высокую частоту нарушений функционального состояния плода, такие как, задержка роста внутриутробного плода - 21\%(373), аномалия развития плода - 4,3\%(79), фетопатия вследствие сахарного диабета - 5,4\%(99), нарушение состояния плода в результате резус-конфликта - 4,5\%(82). 25,3\%(458) - угрожающее состояние плода, которое явилось показанием экстренного преждевременного родоразрешения. Таким образом, состоние 
внутриутробного плода тесно связано с повышением частоты преждевременных родов.

\section{Обсуждение}

Частота преждевременных родов в Казахстане составляет $6,4 \%$, в специализированных организациях родовспоможения - $15 \%$. У трех четверти женщинпреждевременные роды были вызваны состоянием здоровья матери - гипертензивные состояния, преэклампсия, эклампсия, заболевания сердца, крови. Соматические заболевания матери могут быть не только предиктором развития осложнений со стороны матери, но и со стороны внутриутробного плода, что четко показано результатами наших исследований: нарушения функционального состояния внутриутробного плода явились показанием для индукции родов в 25\%. У каждого пятого пациента показанием для индукции родов была задержка развития внутриутробного плода, у каждого четвертого угрожающее состояние плода.

Спонтанные роды в структуре всех преждевременных родов составляют $23,3 \%$, половина из них начинается с преждевременного дородового излития околоплодных вод. В нашем исследовании наличие цервикальной недостаточности (ОШ-7,53;SE-0,22; ДИ(95\%) 0,3-30,0;) - фактор риска, который является статистически значимым в развитии преждевременных родов.

Течение и исход предшествующих беременностей тесно связаны с течением и исходом настоящей беременности: мультипаритет 4 и более(ОШ-1,19; SE - 0,3; ДИ(95\%) 0,72,2;), кесарево сечение (ОШ-1,2;SE - 0,29; ДИ(95\%) 0,7-2,1;), потери беременностей(ОШ-1,65; SE - 0,35; ДИ(95\%) 0,8-3,2;), рождение маловесного к сроку гестации плода(ОШ-2,38; SE 0,37; ДИ (95\%) 1,2-5,1;), преждевременные роды (ОШ-2,66; SE - 0,35; ДИ(95\%) 1,3-5,3;).

Социальный портрет женщин с преждевременными родами выглядит следующим образом: возраст от 20 до 34 лет, преимущественно проживающие в сельской местности, домохозяйки, с низким и средним уровнем образования, повторнородящие, с привычной потерей беременности или предшествующими преждевременными родами, истмикоцервикальную недостаточность. Полученные данные еще раз подтверждают, что оценка риска у пациентов с историей преждевременных родов или потерей беременности требует тщательного наблюдения за состоянием шейки матки в сравнении с пациентами без отягощенного анамнеза по невынашиванию[2].

Следовательно, для Казахстана данные факторы риска имеют значение в наступлении преждевременных родов. Аналогичные данные были изучены в исследовании факторов риска преждевременных родов в Европе [3]. Однако по данным некоторых авторов, возраст матери, место работы, образование не имели статистически значимой связи с преждевременными родами. По результатам этих исследований преждевременное излитие околоплодных вод, многоплодная беременность, гипертензионные состояния, акушерский анамнез, истмикоцервикальная недостаточность и возраст матери более 35 лет в совокупности значительно повышают частоту преждевременных родов[4].

\section{Выводы}

Распространенность преждевременных родов в Казахстане по официальным данными составляет около 6,4\%. В нашем исследование частота преждевременных родов в учреждении, оказывающем выскоспециализироанную помощь,составила 15\% (1806 случаев из 11861 родов).В структуре преждевременных родов преобладают индуцированные роды - \% вследствие ухудшения состояния матери и плода.

Определяющим фактором риска преждевременных родов является состояние здоровья матери, гипертензивные заболевания, болезни сердца, крови. Оздоровление этих женщин является реальным путем снижения частоты преждевременных родов в Казахстане.

Факторами риска развития преждевременных родов являются истмико-цервикальная недостаточность, повторные беременности с паритетом более $4 \mathrm{x}$, наличие преждевременных родов и потерь плода в анамнезе, рождение маловесных детей, возраст матери, низкий уровень образования, проживание в сельской местности.

Планирование семьи, предгравидарная подготовка будущей матери и проведение профилактических мероприятий у беременных групп высокого риска по преждевременным родам может быть условием для снижения частоты преждевременных родов.

\section{Литература}

1. WHO. Information bulletin №363. 2015.

2. Berghella V, Hayes E, Visintine J, Baxter JK. Fetal fibronectin testing for reducing the risk of preterm birth. Cochrane Database Syst. 2008;8(4): CD006843.

3. Ancel, Pierre-Yves; Saurel-Cubizolles Marie-Josephe; Di Renzo, Gian Carlo, Papiernik, Emile; Breart, Gerard. Social Differences of Very Preterm Birth in Europe. American Journal of Epidemiology, 1999;149 (10):908-15.

4. Derakhshi B, Esmailnasab N, Ghaderi E, Hemmatpour S. Risk factor of preterm labor in the West of Iran: a case-control study. Student Research Committee, School of Medicine, Kurdistan University of Medical Science, Sanandaj, Iran. Iranian Journal of Public Health. 2014; 43(4):499-506. 